\title{
Antioxidant activity of plant extracts and their effect on methane fermentation in bioreactors**
}

\author{
Marta Oleszek ${ }^{1 *}$ and Solomiia Kozachok ${ }^{2,3}$ \\ ${ }^{1}$ Institute of Agrophysics, Polish Academy of Sciences, Doświadczalna 4, 20-290 Lublin, Poland \\ ${ }^{2}$ Institute of Soil Sciences and Plant Cultivation, State Research Institute, Czartoryskich 8, 24-100 Puławy, Poland \\ ${ }^{3}$ I Horbachevsky Ternopil State Medical University, Maidan Voli 1, 46001 Ternopil, Ukraine
}

Received January 16, 2018; accepted May 21, 2018

\begin{abstract}
Extracts of Solidago virgaurea L. (European goldenrod), Lavandula angustifolia Mill. (lavender) and Arnica chamissonis Less. (arnica) were tested as potential additives for methane fermentation in bioreactors, as it was hypothesized that their antioxidant properties may improve biogas production efficiency. Hence, methane fermentation of maize silage with the addition of tested extracts was performed in eudiometers, and both the biogas volume and methane content in biogas were measured. In addition, antioxidant properties, such as reducing power and 1,1-diphenyl-2-picrylhydrazyl free radical-scavenging activity, were determined spectrophotometrically. The results showed that only the addition of a goldenrod crude extract caused a significant increase in biogas yield, despite the fact that it presented the lowest antioxidant activity of the three tested species. No significant differences in biogas yield were found between the other two additives and the control. Biogas production efficiency was not correlated with the antioxidant activity of the crude extracts. Hence, the increase in methane fermentation efficiency in the case of goldenrod supplementation might have resulted from some other non-antioxidant compounds occurring in this species.

Keyw ords: biogas, methane fermentation, antioxidant activity, Solidago virgaurea L., Arnica chamissonis Less., Lavendula angustifolia Mill.
\end{abstract}

\section{INTRODUCTION}

The methane fermentation process is utilized for the production of biogas which is one of the renewable energy sources (RES). However, many factors may affect the efficiency of this process, thus influencing the profitability of biogas production. Among these are suitable physicochemical conditions in the fermenter (i.e. $\mathrm{pH}$, temperature and redox potential) and the presence of different inhibitors, stimulators or additives (Hagos et al., 2017).

\footnotetext{
*Corresponding author e-mail: m.oleszek@ipan.lublin.pl

**This work was financed by the Polish National Science Centre, Preludium 8, No. 2014/15/N/NZ9/01127 (2015-2018).
}

The effect of various substances being added to the methane fermentation process has been widely studied. Indeed, a stimulating effect has been noted with the addition of porous materials (biochar, chalk, kaolin), nanoparticles and certain plant specific metabolites (PSM) such as caffeine and saponins (Ganzoury and Allam, 2015; Prabhudessai et al., 2009; Singh et al., 2001; Yadvika et al., 2004). Many PSMs with antioxidant activity are present in biomass, acting as biogas production substrates, but their influence on the methane fermentation process has not yet been fully recognized. The action of some of these has been tested in relation to the methanogenesis process in ruminants (Bhatta et al., 2013; Cieślak et al., 2013, 2014; Patra and Saxena, 2010; Van Nevel and Demeyer, 1996), revealing that in this case methane production is a negative phenomenon due to environmental pollution and the loss of energy from feed.

Broudiscou et al. (2000) investigated the influence of thirteen plant extracts with high flavonoids content on methanogenesis in a continuous culture of rumen microbes. They stated that crude extracts from Lavendula angustifolia (lavender), Arnica chamissonis (arnica) and Solidago virgaurea (European goldenrod) brought about an increase in methane production, and they should be selected for further, and more detailed, evaluation. However, the influence of extracts obtained from these species was not previously evaluated in the context of biogas production by fermenter (via an inoculum derived from a commercial biogas plant), where a high efficiency of methane fermentation was desirable. In turn, Covaliov et al. (2012) pointed out that

(C) 2018 Institute of Agrophysics, Polish Academy of Sciences 
bioactive substances from winery grains, such as antioxidants and membrane-protectors, had a positive effect on the microorganisms involved in methane fermentation and increased biogas production.

Considering the above facts, we aimed to investigate the effect of the addition of methanolic extracts of arnica, lavender and goldenrod on biogas and methane yield, as well as on methane content in the biogas produced by anaerobic digestion in bioreactors. At the same time, by measuring the antioxidant activity of the extracts from the three species, we intended to correlate this property with biogas production efficiency. In doing so, we assumed that biologically active compounds might increase biogas yield due to their antioxidant properties.

\section{MATERIALS AND METHODS}

Maize silage (Zea mays L.) which was cultivated in 2014 at the Experimental Station of the Institute of Soil Science and Plant Cultivation in Osiny (Lublin Voivodship) was used as the substrate of the anaerobic digestion performed in bioreactors. The cultivation methods employed were previously described in detail by Oleszek and Matyka (2017). Methanolic crude extracts from Lavendulae flos, Arnicae flos and Solidaginis virgaureae herba were used as additives to methane fermentation. The dried biomass of the mentioned herbs was obtained from Kawon-Hurt Company, Poland.

The extracts of the tested herbs were prepared according to the procedure described by Pawelec et al. (2013). The following solvents were used for extraction: chloroform HPLC grade, methanol HPLC grade - purchased from Merck (Darmstadt, Germany), ultrapure water obtained in-house with a purification system (Milli-Q ${ }^{\circledR}$ Simplicity 185, Millipore Corp., Billerica, MA), formic acid MS-grade, and eluent additive for LC-MS - purchased from Sigma-Aldrich.

Briefly speaking, $30 \mathrm{~g}$ of plant material was defatted using chloroform in a Soxhlet apparatus until exhaustion. The residue was then extracted under reflux, thrice per $2 \mathrm{~h}$ with $70 \%$ methanol. Subsequently, the methanolic extract was evaporated under reduced pressure, suspended in water, and then lyophilized.

In the next step, the polar fraction content (sugar and simple organic acids) and PSM fraction in the extract were both determined. In so doing, the crude extract was dissolved in water and applied to a $6 \times 10 \mathrm{~cm}, 75 \mu \mathrm{m}$ Cosmosil RP-18 (Nacalai Tesque Inc., Japan) preparative column, preconditioned with acidified water $(0.1 \%$ formic acid). The column with the extract was first washed with $0.1 \%$ formic acid in water, in order to remove the sugars and simple organic acids, and then with a methanol-water (95:5) solution to elute PSM. Finally, the eluates were evaporated and weighted (Krzyżanowska-Kowalczyk et al., 2017). Subsequently, the crude extract was analyzed for antioxidant properties.
Reducing power was determined using the method described by Medini et al. (2014), albeit with a slight modification. Briefly speaking, $1 \mathrm{ml}$ of a crude extract solution at concentrations from 0 to $1500 \mu \mathrm{g} \mathrm{ml}^{-1}$, was adjusted with $2.5 \mathrm{ml}$ phosphate buffer $\left(0.2 \mathrm{~mol} \mathrm{l}^{-1}\right.$ and $\left.\mathrm{pH} 6.6\right)$ and 2.5 $\mathrm{ml}$ of potassium ferricyanide $\left[\mathrm{K}_{3} \mathrm{Fe}(\mathrm{CN})_{6}\right](1 \%$, w/v). This was followed by incubation at $50^{\circ} \mathrm{C}$ for $30 \mathrm{~min}$, after which $2.5 \mathrm{ml}$ of trichloroacetic acid (TCA); $(10 \%, \mathrm{w} / \mathrm{v})$ was added. The obtained solution $(2.5 \mathrm{ml})$ was then mixed with 2.5 $\mathrm{ml}$ of deionised water and $0.5 \mathrm{ml}$ of ferric chloride $\left(\mathrm{FeCl}_{3}\right)$ $(0.1 \%, w / v)$. Finally, the absorbance was measured at 700 $\mathrm{nm}$, and the results were expressed as the crude extract concentration that gave absorbance equal to $0.5\left(\mathrm{EC}_{50}\right)$. Ascorbic acid was used as the reference sample.

Radical-scavenging activity was determined by bleaching a purple solution of 1,1-diphenyl-2-picrylhydrazyl (DPPH) radical, using a method developed by Blois (1958) and described in detail by Sannigrahi et al. (2010). Herein, $3 \mathrm{ml}$ of crude extract solution in methanol at different concentrations was mixed with $1 \mathrm{ml}$ DPPH at a concentration of $0.1 \mathrm{mM}$ in methanol. The mixture was allowed to stand for $15 \mathrm{~min}$, and the absorbance was measured at $517 \mathrm{~nm}$. DPPH radical-scavenging activity was calculated according to the following formula:

$$
\% \text { Inhibition }=\left(A_{0}-A_{1}\right) / A_{0} 100,
$$

where: $A_{0}$ was the absorbance for the reference sample (just DPPH solution) and $A_{1}$ was the absorbance for the tested sample. The results were expressed as $\mathrm{IC}_{50}$ values (the concentration which corresponded to $50 \%$ scavenging activity).

Finally, methane fermentation was performed in accordance with the VDI 4630 protocol (2006), as described in detail by Oleszek et al. (2016). The parameters of the process were established as follows: temperature $37^{\circ} \mathrm{C}$, $\mathrm{pH} \sim 7$, working volume of 0.81 , volatile solids (VS) concentration in fermenting mixture $3 \%$, and substrate to inoculum ratio (S:I) of 1:2 (based on VS). Post-fermentation sludge from the local biogas plant was used as the inoculum. Batch assays of methane fermentation were performed for maize silage with the addition of $80 \mathrm{mg}$ of each lyophilized crude extract. Maize silage and the inoculum alone were used as controls.

During the reference process, biogas yield was measured daily via the liquid displacement method, while methane content was assessed using a GFM 400 series analyser (Gas Data, UK). The process was considered finished when the daily biogas volume was lower than $1 \%$ of its total production. The results for maize silage, both with and without additives, were subtracted from the average result for the inoculum alone and expressed in $\mathrm{dm}^{3}$ (calculated on standard conditions (1013 hPa, $273 \mathrm{~K})$ per $\mathrm{kg}$ of VS of maize silage.

After methane fermentation, the final VS concentrations were established by heating dry samples at $550^{\circ} \mathrm{C}$ in a muffle furnace, and then subtracting the residue mass 
from the mass of the dry sample. The methane yield from the added portion of crude extracts was calculated based on their chemical oxygen demand (COD). This was determined using a LCK 414 cuvette test and a Hach DR 3900 uv-vis spectrophotometer. A theoretical methane potential of $0.35 \mathrm{dm}^{3} \mathrm{CH}_{4}$ per $1 \mathrm{~g}$ of COD was used for calculations (Yang et al., 2010).

Data analysis was performed by means of Statistica 12 software. The antioxidant activity was determined in triplicate, while the methane fermentation was carried out in five replicates. The results were then expressed as the means \pm standard deviations (SD). The significance of differences between crude extracts was evaluated by means of the posthoc Tukey test, at $\mathrm{p}<0.05$.

\section{RESULTS AND DISCUSSION}

The results of the extraction of dry material of the three tested species are presented in Table 1. Herein, the dry matter in these extracts was determined at $8.98,7.08$ and $8.31 \mathrm{~g}$, which accounted for $32.09,23.60$, and $27.71 \%$ of the plant dry materials for arnica, lavender and European goldenrod, respectively.
Moreover, the extracts consisted of polar compounds (sugars and simple organic acids) and PSM.

Lavender was characterized by the highest content of PSM in the crude extract, while arnica was noted as displaying the lowest content. Therefore, the arnica crude extract contained the highest amount of polar constituents (sugars and simple organic acids), while lavender displayed the lowest value.

The crude extracts expressed the concentration-dependent reducing power and radical scavenging activities (Figs 1 and 2). The greatest antioxidant activity was observed for arnica, as evidenced by the lowest values of $\mathrm{EC}_{50}$ and $\mathrm{IC}_{50}$ (Table 2). In contrast, the highest values of these parameters were obtained for goldenrod, indicating that its extract showed the weakest antioxidant activity. The reducing properties of the extracts are generally associated with the presence and concentration of different reductants which break the free radical chain by donating a hydrogen atom or reacting with certain precursors of peroxide (Loganayaki et al., 2013). The highest antioxidant activity of the arnica crude extract, despite the lowest

Table 1. Characteristics of crude extracts

\begin{tabular}{lccc}
\hline Parameter & S. virgaurea & L. angustifolia & A. chamissonis \\
\hline Crude extract $(\mathrm{g})$ & 8.31 & 7.08 & 8.98 \\
Crude extract (\% of dried material) & 27.7 & 23.6 & 32.1 \\
Polar fraction (g) & 4.61 & 3.47 & 5.56 \\
Plant specific metabolites (g) & 3.70 & 3.61 & 3.41 \\
Polar fraction (\% crude extract) & 55.4 & 49.0 & 62.0 \\
Plant specific metabolites (\% crude extract) & 44.4 & 51.0 & 38.0 \\
$\mathrm{COD}\left(\mathrm{g} \mathrm{O}_{2} \mathrm{~g}^{-1} \mathrm{VS}\right)$ & 0.68 & 0.79 & 0.99 \\
\hline
\end{tabular}

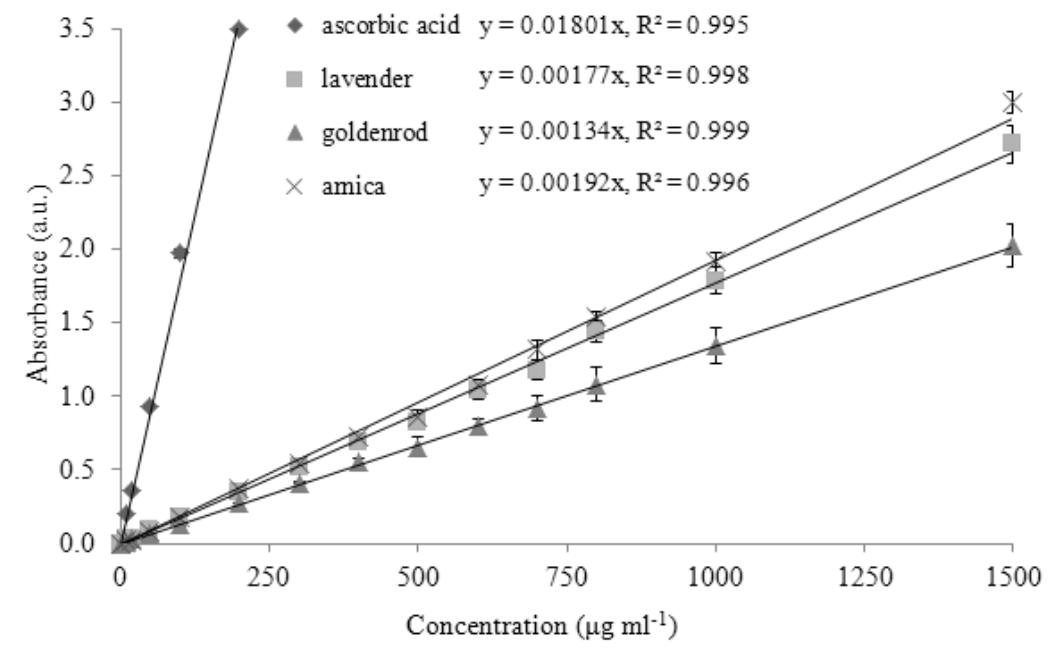

Fig. 1. The reducing power of the crude extracts of goldenrod, lavender, arnica and ascorbic acid, depending on their concentrations. The bars indicate the standard deviations (SD) of three replicates. 


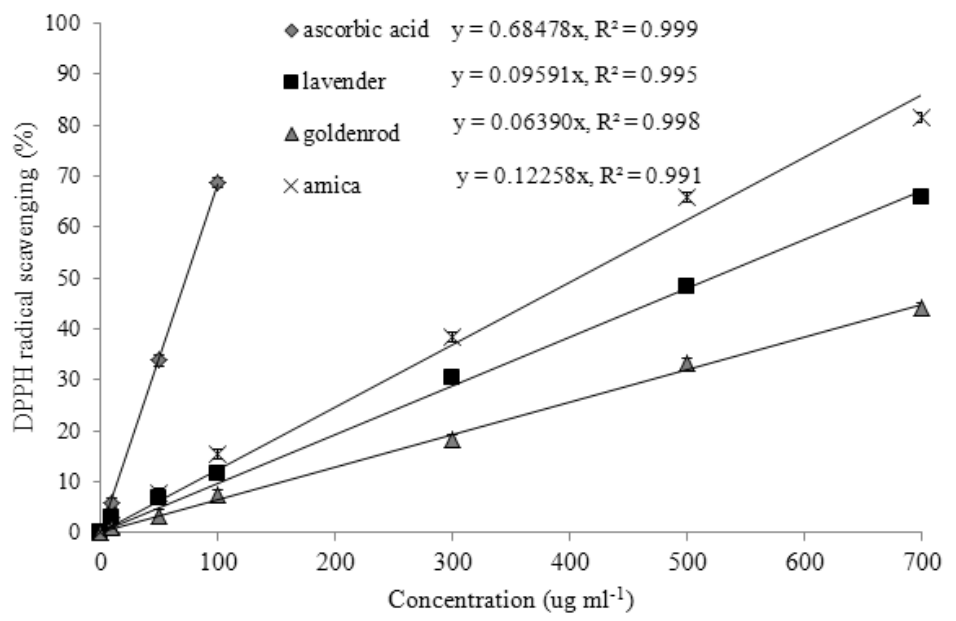

Fig. 2. DPPH radical-scavenging activity of the crude extracts of goldenrod, lavender, arnica and ascorbic acid, depending on their concentrations. The bars indicate the standard deviations (SD) of three replicates.

Table 2. Antioxidant properties of the crude extracts of arnica, lavender and goldenrod

\begin{tabular}{lcc}
\hline Sample & $\begin{array}{c}\text { Reducing power } \\
\text { EC }_{50}\end{array}$ & $\begin{array}{c}\text { Radical- } \\
\text { scavenging } \\
\text { activity IC }\end{array}$ \\
\cline { 2 - 3 } & \multicolumn{2}{c}{$\left(\mu \mathrm{g} \mathrm{ml}^{-1}\right)$} \\
\hline Lavender crude extract & $282.29 \pm 9.77$ & $509.62 \pm 7.51$ \\
Goldenrod crude extract & $355.98 \pm 6.33$ & $767.32 \pm 30.71$ \\
Arnica crude extract & $260.52 \pm 14.77$ & $393.43 \pm 11.77$ \\
Ascorbic acid & $27.82 \pm 0.07$ & $73.61 \pm 6.35$ \\
\hline
\end{tabular}

content of specific metabolites, might suggest the presence of stronger antioxidants in this plant when compared with the other two.

The available literature about arnica phytochemicals indicates the presence of sesquiterpene lactones, which are components of essential oil (helenalin, dihydrohelenalin), and also of flavonoid glycosides (quercetin, patuletin, hyperoside) and phenolic acids (caffeic acid, chlorogenic acid) (Gawlik-Dziki et al., 2011; Leven and Willuhn, 1987; Merfort, 1988, 1992). The main compounds in lavender are monoterpene and sesquiterpenes (linalool, linalyl acetate), flavonoids (luteolin), triterpenoids (ursolic acid), and coumarins (umbelliferone and coumarin) (Rabiei et al., 2014). The goldenrod species also contains flavonoids (rutin, astragalin) and phenolic acids (chlorogenic and rosmarinic acid) but it differs from the other two species in terms of the substantial content of saponins which do not show antioxidant properties (Bader et al., 1995; Rosłoń et al., 2014). Moreover, in contrast to arnica and lavender, goldenrod does not contain the substantial concentrations of essential oils which are known for their antibacterial activities. Broudiscou et al. (2000) reported that hyperoside, luteolin-7-glucoside and rutin are the main compounds present in the crude extracts of arnica, lavender and goldenrod, respectively. The above compounds are known as strong radical scavengers, and their DPPH radical scavenging activity was comparable to ascorbic acid (Piao et al., 2008; Sukito and Tachibana, 2014). The concentration and structural differences of these phenolic compounds, including flavonoids, are responsible for the different antioxidant and radical scavenging activity of the extracts (Burda and Oleszek, 2001).

The results of methane fermentation were presented in Fig. 3. As can be seen, the greatest increase in biogas yield, from 326.6 to $647.5 \mathrm{dm}^{3} \mathrm{~kg}^{-1} \mathrm{VS}$, was caused by the addition of the goldenrod crude extract, while the other two additives did not induce significant changes in the efficiency of methane fermentation of maize silage. The biogas yield of maize silage, as reported in various studies, ranges from $350 \mathrm{dm}^{3} \mathrm{~kg}^{-1} \mathrm{VS}$ to even more than $600 \mathrm{dm}^{3} \mathrm{~kg}^{-1} \mathrm{VS}$, depending on the variety, cultivation conditions, harvest date and methane fermentation parameters (Munsec et al., 2009; Negri et al., 2014; Oslaj et al., 2010).

Methane fermentation with the addition of the European goldenrod crude extract also resulted in the highest removal of VS, as compared to other fermentations, although no significant difference was found with arnica (Fig. 4). These results indicate that the goldenrod extract holds a positive influence on the degree of substrate decomposition under anaerobic conditions.

The present study has also shown that the extracts of the tested plants did not differ much in terms of the content of polar constituents, such as sugars and simple organic acids, which are easily degraded by acetogenic bacteria to acetate, hydrogen and carbon dioxide in the acetogenesis phase of methane fermentation. Moreover, acetate, hydrogen and carbon dioxide are directly used by methanogens to produce methane and carbon dioxide (the main biogas components) (Oleszek and Tys, 2013). As reported by Berry et al. (1987), compounds including an aromatic ring in their 


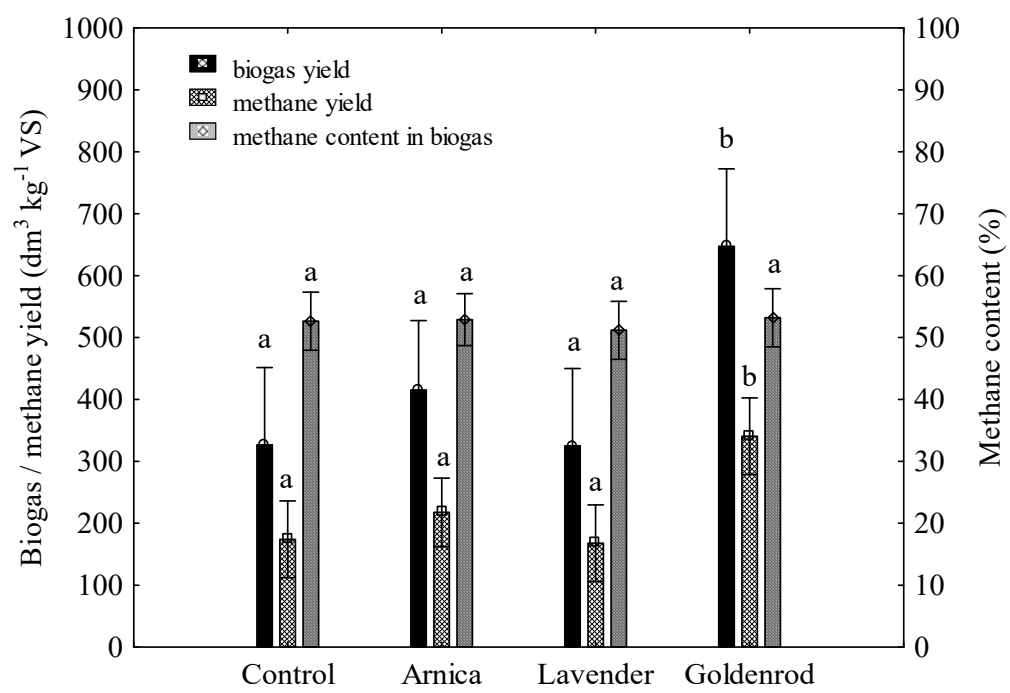

Fig. 3. The biogas yield of maize silage alone (control) and maize silage after adding the crude extracts of arnica, lavender and goldenrod $(100 \mathrm{ppm})$. The bars indicated the standard deviations (SD) of five replicates. The same letters indicate the means that did not differ significantly in Tukey test $(\mathrm{p}<0.05)$ within one series.

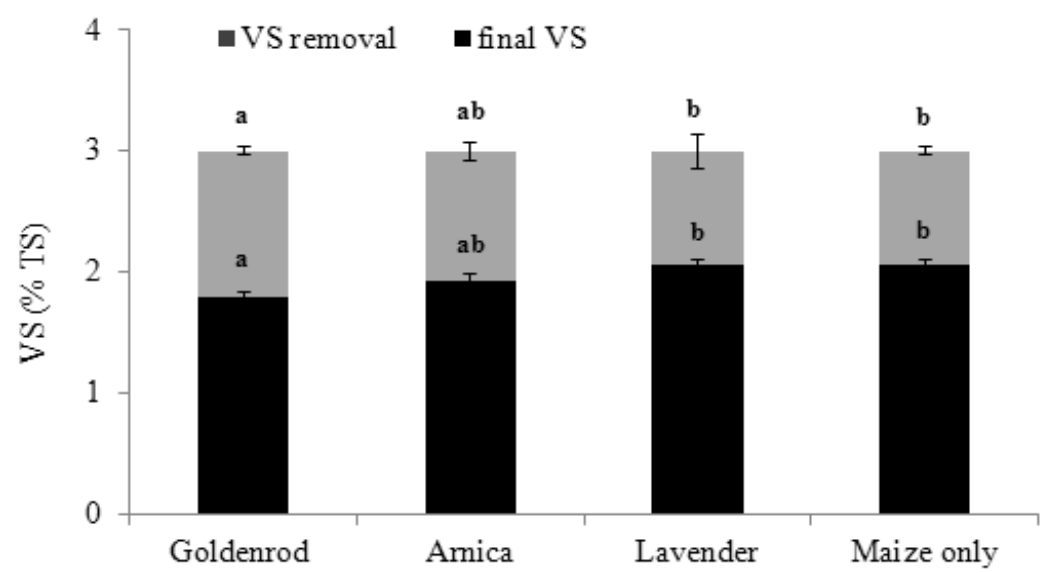

Fig. 4. The concentration of volatile solids (VS) after methane fermentation of maize silage, both with and without the addition of crude extracts and VS removal. Different letters indicate significant differences in the Tukey test results $(\mathrm{p}<0.05)$.

structure (e.g. phenolic compounds) can also be metabolized by microorganisms under anaerobic conditions and are likely to serve as substrates. However, it is worth mentioning that the increase in the biogas yield for goldenrod was much higher than expected, following the addition of $80 \mathrm{mg}$ of extra VS in the form of the tested extract. The COD of the extract of goldenrod, arnica and lavender was $0.68,0.79,0.99 \mathrm{~g} \mathrm{O}_{2} \mathrm{~g}^{-1} \mathrm{VS}$, respectively (Table 1). This means that the maximum methane potential of the added portion of $80 \mathrm{mg}$ of the extracts was $0.019,0.022$, and 0.028 $\mathrm{dm}^{3} \mathrm{CH}_{4}$, respectively, which corresponded to the extra methane yield of $2.37,2.72$, and $3.44 \mathrm{dm}^{3} \mathrm{~kg}^{-1}$ of total VS, respectively (in the form of maize silage and crude extract). This suggests that the extract of European goldenrod served not as a simple digestible substrate for the microorganisms tested but rather as a stimulant.
The positive influence of the goldenrod crude extract is in accordance with a previous study on the co-digestion of goldenrod biomass with maize silage (Oleszek and Krzemińska, 2017). Its results indicated that co-fermentation induced a higher methane yield than the average yield of two mono-fermentations. Likewise, it was stated that the addition of the goldenrod crude extract increased methane yield, compared to the control. Unfortunately, the reason for this phenomenon has remained unexplained and needs further research. In the present study, the goldenrod crude extract showing the lowest antioxidant activity evidences that the stimulating effect on the methane fermentation is not associated with the presence of antioxidant compounds but with substances belonging to a different group of PSM. As mentioned above, apart from the phenolics which are responsible for antioxidant properties, the goldenrod crude 
extract also contains a substantial amount of saponins. A positive effect of saponins on anaerobic digestion was previously observed (Singh et al., 2001; Zhou et al., 2015; Huang et al., 2016). Furthermore, Zhou et al. (2015) reported that saponins improved the acetogenesis steps of the methane fermentation of waste activated sludge, simplifying the protein and carbohydrate solubilisation and the formation on volatile fatty acids (VFA). These groups of compounds, like bio-surfactants, intensify the permeability of the cells of the substrate tissues, and bring about an increase in the transfer of intracellular polymeric substances out of the cell, which can be then more easily available for microorganism biodegradation (Oleszek and Hamed, 2000).

It is also possible that the easily degradable additives (added and consumed at the very beginning of the process) facilitated the survival and development of microorganisms when the main substrate was not yet hydrolyzed. Therefore, the crude extract was capable of indirectly enhancing the decomposition of maize and the final methane production. The lack of any effect of the addition of lavender and arnica crude extracts may have come about either by the absence of stimulants or by the presence of inhibitors. Each crude extract contains lots of substances, among which some may positively and others negatively impact on the process. For example, Akassou et al. (2010) showed the inhibitory effect of polyphenols on the efficiency of anaerobic digestion of wine distillery wastewater, while Herrmann and Janke (2001) did not see any significant effect of rutin and hesperidin addition on the methane production from brewery wastewater. Furthermore, Popp et al. $(2015,2016)$ evidenced that coumarins and alkaloid gramine inhibited methane production, but the microorganisms of fermentation were able to adapt to unfavourable conditions. Therefore, the presence of coumarins in lavender may partly cause the lack of a positive effect of its crude extract addition in this study. It should be noted that most biogas plants work in a semi-continuous mode which differs greatly from the batch mode. Hence, the results obtained through batch assays should be verified in semicontinuous methane fermentation tests.

\section{CONCLUSIONS}

1. The results indicate that the strongest antioxidant activity was shown by the crude extract of arnica, while the weakest was attributable to goldenrod. Simultaneously, the addition of the goldenrod crude extract generated a significant increase in the efficiency of the methane fermentation process and the greatest reduction of volatile solids (VS) concentration.

2. Given the above, it can be stated that either antioxidant properties did not have a positive influence on the biogas and methane yield, as had been hypothesized, or that the effect was thwarted by the presence of inhibitors.
3. Moreover, the increase in biogas production efficiency induced by the addition of the goldenrod crude extract might have resulted from the action of the non-antioxidant compounds such as saponins, which can be found in this plant in substantial amounts.

Conflict of interest: The Authors do not declare conflict of interest.

\section{REFERENCES}

Akassou M., Kaanane A., Crolla A., Kinsley C., 2010. Statistical modelling of the impact of some polyphenols on the efficiency of anaerobic digestion and the co-digestion of the wine distillery wastewater with dairy cattle manure and cheese whey. Water Sci. Technol., 62(3), 475-483.

Bader G., Wray V., and Hiller K., 1995. The main saponins from the aerial parts and the roots of Solidago virgaurea subsp. virgaurea. Planta Medica, 61(02), 158-161

Berry D.F., Francis A.J., and Bollag J.M., 1987. Microbial metabolism of homocyclic and heterocyclic aromatic compounds under anaerobic conditions. Microbiol. Reviews, 51(1), 43-59.

Bhatta R., Saravanan M., Baruah, L., Sampath K.T., and Prasad C.S., 2013. Effect of plant secondary compounds on in vitro methane, ammonia production and ruminal protozoa population. J. Appl. Microbiol., 115(2), 455-465.

Blois MS., 1958. Antioxidant determination by the use of a stable free radical. Nature, 29, 1199-1200.

Broudiscou L.P., Papon Y., and Broudiscou A.F., 2000. Effects of dry plant extracts on fermentation and methanogenesis in continuous culture of rumen microbes. Animal Feed Sci. Technol., 87(3), 263-277.

Burda S. and Oleszek W., 2001. Antioxidant and antiradical activities of flavonoids. J. Agric. Food Chem., 49, 27742779.

Cieślak A., Szumacher-Strabel M., Stochmal A., and Oleszek W., 2013. Plant components with specific activities against rumen methanogens. Animal, 7(s2), 253-265.

Cieślak A., Zmora, P., Stochmal A., Pecio L., Oleszek W., PersKamczyc E., Szczechowiak J., Nowak A., and Szumacher-Strabel M., 2014. Rumen antimethanogenic effect of Saponaria officinalis L. phytochemicals in vitro. J. Agric. Sci., 152(6), 981-993.

Covaliov V., Bobeica V., Covaliova O., Nenno V., Ungureanu D., and Senicovskaya I., 2012. Ecologically and economically efficient strategy of wastewater treatment. Ecoterra, $30,1-7$.

Ganzoury M.A. and Allam N.K., 2015. Impact of nanotechnology on biogas production: a mini-review. Renewable and Sustainable Energy Reviews, 50, 1392-1404.

Gawlik-Dziki U., Swieca M., Sugier D., and Cichocka J., 2011. Comparison of in vitro lipoxygenase, xanthine oxidase inhibitory and antioxidant activity of Arnica montana and Arnica chamissonis tinctures. Acta Scientiarum Polonorum, Hortorum Cultus, 10(3), 15-27.

Hagos K., Zong J., Li D., Liu C., and Lu X., 2017. Anaerobic co-digestion process for biogas production: Progress, challenges and perspectives. Renewable and Sustainable Energy Reviews, 76, 1485-1496. 
Herrmann A.P. and Janke H.D., 2001. Cofermentation of rutin and hesperidin during two-stage anaerobic pre-treatment of high-loaded brewery wastewater. Water Res., 35(11), 2583-2588.

Huang X., Mu T., Shen C., Lu L., and Liu J., 2016. Alkaline fermentation of waste activated sludge stimulated by saponin: volatile fatty acid production, mechanisms and pilotscale application. Water Sci. Technol., 74(12), 2860-2869.

Krzyżanowska-Kowalczyk J., Kolodziejczyk-Czepas J., Kowalczyk M., Pecio L, Nowak P., and Stochmal A., 2017. Yunnaneic acid B - a component of Pulmonaria officinalis extract prevents the peroxynitrite-induced oxidative stress in vitro. J. Agric. Food Chem., 65(19), 3827-3834.

Leven W. and Willuhn G., 1987. Sesquiterpene lactones from Arnica chamissonis less.: VI. Identification and quantitative determination by high-performance liquid and gas chromatography. J. Chromatography, A, 410, 329-342.

Loganayaki N., Siddhuraju P., and Manian S., 2013. Antioxidant activity and free radical scavenging capacity of phenolic extracts from Helicteres isora L. and Ceiba pentandra L. J. Food Sci. Technol., 50(4), 687-695.

Medini F., Fellah H., Ksouri R., and Abdelly C., 2014. Total phenolic, flavonoid and tannin contents and antioxidant and antimicrobial activities of organic extracts of shoots of the plant Limonium delicatulum. J. Taibah University for Sci., $8(3), 216-224$

Merfort I., 1988. Acetylated and other flavonoid glycosides from Arnica chamissonis. Phytochemistry, 27(10), 3281-3284.

Merfort I., 1992. Caffeoylquinic acids from flowers of Arnica montana and Arnica chamissonis. Phytochemistry, 31(6), 2111-2113.

Munsec B., Vindis P., Janzekovic M., Brus M., and Cus F., 2009. Analysis of different substrates for processing into biogas. J. Achievements in Materials and Manufacturing Eng., 37(2), 652-659.

Negri M., Bacenetti J., Massimo B., Manfredini A., Cantore A., and Bocchi S., 2014. Biomethane production from different crop systems of cereals in Northern Italy. Biomass and Bioenergy, 63, 321-329.

Oleszek M. and Krzemińska I., 2017. Enhancement of biogas production by co-digestion of maize silage with common goldenrod rich in biologically active compounds. BioResources, 12(1), 704-714.

Oleszek M. and Matyka M., 2017. Nitrogen fertilization level and cutting affected lignocellulosic crops properties important for biogas production. BioResources, 12(4), 8565-8580.

Oleszek M. and Tys J., 2013. Lab scale measurement of biogas yield. Przemysł Chemiczny, 92(1), 126-130.

Oleszek M., Tys J., Wiącek D., Król A., and Kuna J., 2016. The possibility of meeting greenhouse energy and $\mathrm{CO}_{2}$. BioEnergy Res., 9(2), 624-632.

Oleszek W. and Hamed A., 2000. Saponin-based surfactants. In: Surfactants from Renewable Resources (Eds M. Kjellin, I. Johansson). J. Wiley Press, Chichester, United Kingdom.

Oslaj M., Mursec B., and Vindis P., 2010. Biogas production from maize hybrids. Biomass Bioenergy, 34(11), 15381545 .

Patra A.K. and Saxena J., 2010. A new perspective on the use of plant secondary metabolites to inhibit methanogenesis in the rumen. Phytochemistry, 71(11), 1198-1222.
Pawelec S., Jędrejek D., Kowalczyk M., Pecio L., Masullo M., Piacente S., Macías F.A., Simonet A.M., Oleszek W., and Stochmal A., 2013. Triterpene saponins from the aerial parts of Trifolium medium L. var. sarosiense. J. Agric. Food Chem., 61(41), 9789-9796.

Piao M.J., Kang K.A., Zhang R., Ko D.O., Wang Z.H., You H.J., Kim H.S., Kim J.S., Kang S., and Hyun J.W., 2008. Hyperoside prevents oxidative damage induced by hydrogen peroxide in lung fibroblast cells via an antioxidant effect. Biochimica et Biophysica Acta (BBA)-General Subjects, 1780 (12), 1448-1457.

Popp D., Harms H., and Sträuber H., 2016. The alkaloid gramine in the anaerobic digestion process - inhibition and adaptation of the methanogenic community. Appl. Microbi. Biotechnol., 100(16), 7311-7322.

Popp D., Schrader S., Kleinsteuber S., Harms H., and Sträuber H., 2015. Biogas production from coumarin-rich plants inhibition by coumarin and recovery by adaptation of the bacterial community. FEMS Microbiology Ecology, 91, 9, $1-9$.

Prabhudessai V., Ganguly A., and Mutnuri S., 2009. Effect of caffeine and saponin on anaerobic digestion of food waste. Annals of Microbiol., 59(4), 643-648.

Rabiei Z., Rafieian-Kopaei M., Mokhtari S., Alibabaei Z., and Shahrani M., 2014. The effect of pretreatment with different doses of Lavandula officinalis ethanolic extract on memory, learning and nociception. Biomedicine Aging Pathology, 4(1), 71-76.

Rosłoń W., Osinska E., Mazur K., and Geszprych A., 2014. Chemical characteristics of European goldenrod (Solidago virgaurea L. subsp. virgaurea) from natural sites in Central and Eastern Poland. Acta Sci. Pol., Hortorum Cultus, 13(1), 55-65.

Sannigrahi S., Mazuder U.K., Pal D.K., Parida S., and Jain S., 2010. Antioxidant potential of crude extract and different fractions of Enhydra fluctuans Lour. Iranian J. Pharmaceutical Res., IJPR, 9(1), 75-82.

Singh S., Kumar S., Jain M.C., and Kumar D., 2001. Increased biogas production using microbial stimulants. Bioresource Technol., 78(3), 313-316.

Sukito A. and Tachibana S., 2014. Isolation of hiperoside and isoquercitrin from Camellia sasanqua as antioxidant agents. Pakistan J. Biological Sci., 1-8.

Van Nevel C.J. and Demeyer D.I., 1996. Control of rumen methanogenesis. Environ. Monitoring Assess., 42(1-2), 73-97.

VDI 4630, 2006. Fermentation of organic materials. Characterisation of the substrate, sampling, collection of material data, fermentation tests, Verein Deutscher Ingenieure Press, Düsseldorf, Germany.

Yadvika S., Sreekrishnan T.R., Kohli S., and Rana V., 2004. Enhancement of biogas production from solid substrates using different techniques - a review. Bioresource Technol., 95 (1), 1-10.

Yang M.I., Edwards E.A., and Allen D.G., 2010. Anaerobic treatability and biogas production potential of selected inmill streams. Water Sci. Technol., 62(10), 2427-2434.

Zhou A., Luo H., Varrone C., Wang Y., Liu W., Wang A., and Yue X., 2015. Enhanced anaerobic digestibility of waste activated sludge by plant-derived biosurfactant. Process Biochem., 50(9), 1413-1421. 